\title{
Grape seed extract ameliorates bleomycin-induced mouse pulmonary fibrosis
}

\author{
Qi Liu' ${ }^{\mathrm{a}, 1}$, Jun-xia Jiang, ${ }^{\mathrm{b}, 1}$, Ya-nan Liu ${ }^{\mathrm{a}}$, Ling-tian Ge ${ }^{\mathrm{a}}$, Yan Guan ${ }^{\mathrm{b}}$, Wei Zhao ${ }^{\mathrm{b}}$, \\ Yong-liang Jia ${ }^{\mathrm{b}}$, Xin-wei Dong ${ }^{\mathrm{b}}$, Yun Sun ${ }^{\mathrm{a}, *}$, Qiang-min Xie ${ }^{\mathrm{b}, *}$ \\ ${ }^{a}$ Medical College of Yangzhou University, 11 Huaihai Road, Yangzhou 225001, China \\ ${ }^{\mathrm{b}}$ Key Laboratory of Respiratory Drugs Research, Zhejiang University School of Medicine, Hangzhou 310058, China
}

\section{H I G H L I G H T S}

- Bleomycin induces pulmonary fibrosis in mice.

- Grape seed extract (GSE) reduces cytokines and inflammatory cell infiltration.

- GSE ameliorates TGF- $\beta$ and MMP-9 expression.

- GSE inhibits lung fibrotic markers and improves pulmonary function.

- GSE prevents bleomycin-induced pulmonary fibrosis in mice through its anti-inflammatory and anti-fibrotic effects.

\section{A R T I C L E I N F O}

\section{Article history:}

Received 3 January 2017

Received in revised form 3 March 2017

Accepted 10 March 2017

Available online 12 March 2017

\section{Keywords:}

Bleomycin

Pulmonary toxicology

Lung inflammation

Pulmonary fibrosis

Grape seed extract

Anti-inflammation

Anti-fibrotic effect

\section{A B S T R A C T}

Pulmonary fibrosis is common in a variety of inflammatory lung diseases, such as interstitial pneumonia, chronic obstructive pulmonary disease, and silicosis. There is currently no effective clinical drug treatment. It has been reported that grape seed extracts (GSE) has extensive pharmacological effects with minimal toxicity. Although it has been found that GSE can improve the lung collagen deposition and fibrosis pathology induced by bleomycin in rat, its effects on pulmonary function, inflammation, growth factors, matrix metalloproteinases and epithelial-mesenchymal transition remain to be researched. In the present study, we studied whether GSE provided protection against bleomycin (BLM)-induced mouse pulmonary fibrosis. ICR strain mice were treated with BLM in order to establish pulmonary fibrosis models. GSE was given daily via intragastric administration for three weeks starting at one day after intratracheal instillation. GSE at 50 or $100 \mathrm{mg} / \mathrm{kg}$ significantly reduced BLM-induced inflammatory cells infiltration, proinflammatory factor protein expression, and hydroxyproline in lung tissues, and improved pulmonary function in mice. Additionally, treatment with GSE also significantly impaired BLMinduced increases in lung fibrotic marker expression (collagen type I alpha 1 and fibronectin 1) and decreases in an anti-fibrotic marker (E-cadherin). Further investigation indicated that the possible molecular targets of GSE are matrix metalloproteinases-9 (MMP-9) and TGF- $\beta 1$, given that treatment with GSE significantly prevented BLM-induced increases in MMP- 9 and TGF- $\beta 1$ expression in the lungs. Together, these results suggest that supplementation with GSE may improve the quality of life of lung fibrosis patients by inhibiting MMP-9 and TGF- $\beta 1$ expression in the lungs.

(C) 2017 Elsevier B.V. All rights reserved.

\footnotetext{
* Corresponding authors.

E-mail addresses: jgz7718@sina.com (Y. Sun), xieqm@zju.edu.cn (Q.-m. Xie).

1 QL and JXJ contributed equally to this work.
}

\section{Introduction}

The patients with Idiopathic pulmonary fibrosis (IPF) have a median survival of three to five years from diagnosis, and causes complications in interstitial pneumonia (King et al., 2001; Raghu, 2011). Though its etiology remains unknown, potential risk factors include cigarette smoking, gastroesophageal reflux, and certain types of environmental exposure (Raghu et al., 2011). Its 
pathophysiology is currently thought to involve epithelial injury with abnormal wound healing. The initial conception of the pathogenic process in IPF is thought to be partially inflammatory, resulting in the consideration of broad immunosuppression as a potential therapy. However, the PANTHER trial (Prednisone, Azathioprine and $N$-acetylcysteine: A Study That Evaluates Response in IPF) demonstrated that prednisone, azathioprine, and $\mathrm{N}$-acetylcysteine (NAC) resulted in increased mortality when compared with placebo (Raghu et al., 2012). Additionally, NAC alone was not beneficial to patients with IPF who had mild to moderate impairment of lung function (Martinez et al., 2014).

The recently updated American Thoracic Society/European Respiratory Society/Japanese Respiratory Society/Latin American Thoracic Society (ATS/ERS/JRS/ALAT) clinical practice guidelines for treatment of IPF recommend against the use of warfarin, imatinib, ambrisentan or combination prednisone, azathioprine, and NAC (Raghu et al., 2015). Due to moderate confidence in the effect estimates associated with the use of pirfenidone or nintedanib, these guidelines provide a conditional recommendations for their use in the treatment of IPF (Raghu et al., 2015). Based on data from clinical trials of nintedanib or pirfenidone, patients can anticipate a slowing in disease progression, as assessed by forced vital capacity, and may show some improvement in symptoms. There are no data to guide the initiation of therapy in elderly patients, or those with very mild or severely reduced lung function or significant comorbidities, as these patients did not fit the inclusion criteria of pivotal trials. Additionally, patients prescribed nintedanib or pirfenidone should be educated on the potential adverse effects, need for dose adjustments, behavioral modifications and therapies to improve tolerability, and the need for regular monitoring of hepatic functions. Severe liver and gastrointestinal disturbances and hypersensitivity reactions may lead cessation of these medications.

Due to increasing IPF incidence, as well as the current drug inefficacy and side effects, there is an urgent need for developing new drugs for the treatment of IPF (Raghu et al., 2015). Recently, interest has accumulated regarding the use of natural products as a supplementary and regenerative therapeutic drug for IPF. A number of studies have confirmed a variety of compositions from Chinese medicine, which can improve pulmonary fibrosis in clinical and animal studies. Indeed, some compositions, such as schisandrin B, artesunate, triptolide, curcumin, sophocarpidine, grape seed extract, tanshinone IIA, and glycyrrhizic acid, have been studied in the treatment of IPF (Gao et al., 2015; He et al., 2015; Hemmati et al., 2008; Wei and Li, 2013). Among them is Vitis vinifera, a nutritious fruit. Its seeds contain a variety of active ingredients, such as proanthocyanidins, anthocyanins, procyanidines, epicatechin, resveratrol, and quercetin (Garavaglia et al., 2016; Nassiri-Asl and Hosseinzadeh, 2009). More importantly, a three-month, long-term toxicity test in rats showed that GSE is minimally toxic (Bentivegna and Whitney, 2002; Wren et al., 2002). Additionally, GSE is a nutritional supplement. In some individuals with IPF, nutrition supplement can be useful in achieving optimal nutritional status in order to improve pulmonary function (Sirinupong and Yang, 2015). From the abovementioned presumptions, GSE may improve lung inflammation and fibrotic lesions associated with pulmonary fibrosis. Research has shown that GSE has significant effects on bleomycin (BLM) or silica-induced lung fibrotic lesions in a rat model. GSE decrease oxidative stress response and neutrophil infiltration into lung tissues during the inflammatory process (Agackiran et al., 2012; Khazri et al., 2016). Although GSE improves the lung collagen deposition and fibrosis pathology induced by bleomycin in rat (Bagnato and Harari, 2015; Hemmati et al., 2006; Schwarzenberg et al., 2016), its effects on pulmonary function, inflammation, growth factors, matrix metalloproteinases and epithelial- mesenchymal transition remain to research. Additionally, epithelial-mesenchymal transition (EMT) is a key element in pulmonary fibrotic diseases. The effects of GSE on EMT also need a further research.

BLM is an antibiotic, which has been used in cancer chemotherapy. Pulmonary fibrosis is one of the major side effects of BLM. BLM-induced lung fibrosis has become a useful experimental model in animals for interstitial pneumonitis and pulmonary fibrosis. In this study, GSE is found to serve as an anti-inflammatory and antifibrotic agent against pulmonary fibrosis in mice. In vivo results show that BLM-induced pulmonary fibrosis causes body weight loss, lung function deterioration, and lung histopathology abnormalities with collagen deposition in mice. GSE effectively attenuated inflammatory factors and fibrotic factors, including epithelial-mesenchymal transition (EMT) by inhibiting upregulation of TGF- $\beta 1$. In the present study, determined whether GSE was effective against BLM-induced inflammatory and fibrotic lesions in a mouse model, and confirmed its potential mechanisms. In addition, the effects of GSE were compared with dexamethasone, a potent glucocorticoid antiinflammatory drug.

\section{Materials and methods}

\subsection{Animal care and experimental procedures}

According to the previous studies (Xia et al., 2016; Yara et al., 2001), we choose female ICR mice (weighing 18-22 g), and purchased them from SLAC Laboratory Animal Co., Ltd. (Shanghai, China). The animals were housed in isolated ventilated cages (4-5 mice/cage) under a 12-h light/12-h dark cycle and received food and water ad libitum. All the animal experiments performed in this study were approved by the Institutional Animal Care and Use Committee of Zhejiang University. After 5 days acclimatized, a total of 50 mice were randomly allocated into 5 groups of 10 mice/ group; control group (only phosphate buffer saline, PBS), model group (BLM + saline), BLM + GSE $50 \mathrm{mg} / \mathrm{kg}$ group, BLM + GSE $100 \mathrm{mg} / \mathrm{kg}$, and $\mathrm{BLM}+$ dexamethasone (DXM) $0.5 \mathrm{mg} / \mathrm{kg}$, as a positive control, dosage and administration route referenced Shi and colleagues report (Shi et al., 2014). The mice were anesthetized by intraperitoneal injection of $3 \%$ pentobarbital sodium $(10 \mathrm{~mL} / \mathrm{kg})$. The pulmonary fibrosis model was performed via intratracheal instillation of BLM ( $2 \mathrm{mg} / \mathrm{kg}$, volume $20 \mu \mathrm{L} / 20 \mathrm{~g}$ BW) dissolved in sterile PBS. Animals in the control group were given the same amount of PBS without BLM. The model mice were treated with saline $(0.2 \mathrm{~mL} / 20 \mathrm{~g} B W)$ by intragastric administration. The other mice were treated with DXM (Tianyao Pharmaceutical Co., Wuhan, Hubei Province, China) at $0.5 \mathrm{mg} / \mathrm{kg}$, or GSE at 50 or $100 \mathrm{mg} / \mathrm{kg}$ by intragastric administration $(0.2 \mathrm{~mL} / 20 \mathrm{~g}$ BW) daily for three weeks starting at one day after intratracheal instillation of BLM. The dose of GSE was decided by referencing a previous report (Yoo et al., 2011) because the doses are safe and effective. GSE capsules (Preparation specifications: $300 \mathrm{mg} / \mathrm{capsule}$, containing 95\% polyphenois, from General Nutrition Centers, Inc. Pittsburgh, PA, USA. Batch number: 4411HP1810) were broken apart to obtain the GSE powder. Then, we weighted GSE, and dissolved GSE in saline solution. The body weight of each mouse was measured and recorded every three days. Mice were euthanized through an intraperitoneal injection of $40 \mathrm{mg} / \mathrm{kg}$ pentobarbital sodium $24 \mathrm{~h}$ after the last drug treatment. The left Lung was ligatured with nylon wire, and the right Lung tissues lavaged with PBS $3 \times 0.5 \mathrm{~mL}$. Bronchial alveolar lavage fluid (BALF) was collected and centrifuged at $500 \times \mathrm{g}$ for $10 \mathrm{~min}$ at $4{ }^{\circ} \mathrm{C}$. The supernatant was stored at $-80^{\circ} \mathrm{C}$ for measuring TGF- $\beta 1$ protein and toxicity marker lactate dehydrogenase (LDH). The pelleted BALF cells were resuspended in PBS, and the total number of leukocytes was counted in a Neubauer 
chamber. Two hundred cells from BALF stained with WrightGiemsa were counted under a light microscope. The total number of each cell type was determined by multiplying the percentage of each cell type by the total number of cells. The upside of the left lung lobe was cut for measurement of hydroxyproline (HYP), proinflammatory cytokines, and fibrotic factors levels. The bottom of the left lung lobe was preserved in $10 \%$ formalin for immunohistochemistry and histologic examination.

\subsection{Determination of pulmonary function}

A commercially available plethysmograph, acquisition software, and mouse-sized plethymograph chambers (Buxco Electronics, Troy, NY), were used for total pulmonary airflow analysis in unrestrained conscious mice. This system allows measurement of the differential pressure within the chambers cause by the animal breathing. Pressure differences between the chambers containing individual animals and a reference chamber were used to extrapolate minute volume, tidal volume, breathing frequency, and enhanced pause (Penh) (Hoymann, 2007). Penh is a function of total pulmonary airflow during the respiratory cycle and is described by the following equation: Penh $=[(\mathrm{Te} / \mathrm{Tr}-1) \times(\mathrm{PEF} /$ PIF)], where PEP is the peak expiratory pressure, PIP is the peak inspiratory pressure, and pause is a component of expiration time (Te/Tr-1). This parameter is dependent on the breathing pattern and correlates with airway resistance, as measured by traditional invasive techniques with ventilated mice (Hoymann, 2007). According to Qin et al. (2012), twenty-four hours after the last drug treatment, a mouse was acclimatized to the plethysmograph chambers for $10 \mathrm{~min}$ prior to the evaluations. The Penh values of spontaneously breathing mice were measured within a $3 \mathrm{~min}$ period using Buxco whole-body plethysmography. Its averaged value was used as the read out. Though Penh values is correlate with pulmonary resistance, it is still controversial that Penh is a valid indicator of airway resistance (Dominguez-Fandos et al., 2014; Kim et al., 2013; Lundblad et al., 2007; Luo et al., 2014; Verheijden et al., 2014)

\subsection{Histopathological and immunohistochemical examination}

The bottom of the left lung lobe was preserved in $10 \%$ formalin for immunohistochemistry and histologic examination (Section 2.1). The tissue was sectioned within paraffin-embedded blocks, and stained with Hematoxylin and Eeosin (H\&E) to evaluate inflammatory cell infiltration using light microscopy, based on the peribronchial cell counts and the severity of the infiltration of inflammatory cells. A 5-point scoring system was used as described previously (Mikawa et al., 2003). Lung tissues were stained with Masson's trichrome to visualize the deposition of collagen fibers. The severity of pulmonary fibrosis was evaluated by the blind semi-quantitative Ashcroft grading system (Ashcroft et al., 1988). The criterion for grading the severity of pulmonary fibrosis includes the thickness of alveolar walls and collagen deposition. Formalin-fixed pulmonary tissues were processed for immunohistochemistry of metal matrix proteinase-9 (MMP-9), tissue inhibitor of metalloproteinase-1 (TIMP-1), E-cadherin, collagen type I alpha 1 (COL1A1), and fibronectin 1 (FN1). Immunohistochemistry was carried out, according to the guidelines provided, with the Streptavidin-Biotin Complex kit (Boster Bio-engineering Ltd. Co., Wuhan, China), using a 1:200 dilution of anti-MMP-9, TIMP-1, Ecadherin, COL1A1, and FN1 antibody (Santa Cruz, CA, USA). The MMP-9, TIMP-1, E-cadherin, COL1A1, and FN1 staining was quantified using Image Pro 6.1 software. All the analyses were performed in a blind fashion.
2.4. Determination of hydroxyproline in lung tissues, and TGF- $\beta 1$ and $L D H$ in $B A L F$

Collagen deposition was estimated by determining HYP content in the left lung. Lung tissue samples of $100 \mathrm{mg}$ were hydrolyzed with $1 \mathrm{~mL}$ of hydrolysate and boiled for $20 \mathrm{~min}$, and then quantified with a HYP kit (Jiancheng Bioengineering Institute, Nanjing, Jiangsu Province, China). Briefly, samples were centrifuged at $600 \mathrm{~g}$ for $10 \mathrm{~min}$ at $4{ }^{\circ} \mathrm{C}$. Then, the supernatant was used to measure HYP content according to the manufacturer's instructions. According to the calculation method of the instruction, following formula: HYP $(\mu \mathrm{g} / \mathrm{mg}$ wet weight of tissue $)=($ absorbancy of test tube - absorbancy of blank tube)/(absorbancy of standard tube-absorbancy of blank tube) $\times$ content of standard tube $(5 \mu \mathrm{g} / \mathrm{mL}) \times$ volume of hydrolysate $(10 \mathrm{~mL}) /$ wet weight of tissue $(\mathrm{mg})$. To measure TGF- $\beta 1$ protein expression in BALF, an enzymelinked immunosorbent assay (ELISA) kit (Boster, Wuhang, China and Jiancheng Bioengineering Institute, Nanjing, Jiangsu Province, China) was used according to the manufacturer's instructions. The lactate dehydrogenase (LDH) activities in the BALF were evaluated as a marker of cytotoxicity, assayed using the LDH kit (Jiancheng Bioengineering Institute, Nanjing, Jiangsu Province, China) and read out by a standard spectrophotometric method at the wavelength of $450 \mathrm{~nm}$.

\subsection{RNA isolation and quantitative $P C R$}

The methods for RNA isolation and quantitative PCR were described in our previous work (Shen et al., 2014). Briefly, total RNA of the upside of left lung lobe tissues was extracted with TRIzol reagent (Takara Bio, Dalian, China). All PCR primers were purchased from Shanghai Bioengineering (Shanghai, China). All of the primers were checked using a basic local alignment search tool in order to determine their selectivity. Real-time PCR cycling was conducted (7500 Real-Time PCR System; Applied Biosystems, Carlsbad, CA, USA) under the following conditions: The PCR mixture consisted of $10.4 \mu \mathrm{L}$ of SYBR GreenMasterMix, $0.4 \mu \mathrm{L}$ of both the sense and antisense primers, $2.0 \mu \mathrm{L}$ of the sample cDNA solution, and distilled water to obtain a final volume of $20 \mu \mathrm{L}$. The program for chymase was conducted as follows: A denaturation step at $95^{\circ} \mathrm{C}$ for $40 \mathrm{~s}$ and 40 cycles of $95^{\circ} \mathrm{C}$ for $10 \mathrm{~s}, 58^{\circ} \mathrm{C}$ for $10 \mathrm{~s}$, and $72{ }^{\circ} \mathrm{C}$ for $34 \mathrm{~s}$. The primer sequences are described in Table 1 , and $\beta$-actin was used as an internal control.

Table 1

Primers for quantitative real-time PCR analyses.

\begin{tabular}{ll}
\hline Genes & Primer sequences $\left(5^{\prime}-3^{\prime}\right)$ \\
\hline E-cadherin & F: ATCCTCGCCCTGATT \\
& R: ACCACCGTTCTCCTCCGTA \\
COL1A1 & F: TGGAGAGAGAGGTGAACAAGG \\
& R: CATCACCCTTAGCACCATCG \\
FN1 & F: TCCAAGCGGAGAGAGT \\
& R: GTGGGTGTGACCTGAG \\
IL-6 & F: ACCCTGGTGTCACCCTGTTC \\
& R: GTGTTGTCTTGTTGCGTAAG \\
IL-1 $\beta$ & F: GCTTCAGGCAGGCAGTAT \\
& R: ACAAACCGCTTTCCATCT \\
TIMP-1 & F: TGAGGGCTGTCTTTTGACG \\
& R: TGCGTGCTGGTGATCCTCTTGT \\
MMP-9 & F: AATCTCTTCTAGAGACTGGGAAGGAG \\
$\beta$-actin & R: AGCTGATTGACTAAAGTAGCTGGA \\
& F: CTGCCCTGTATGCCTCTG \\
& R: ATGTCACGCACGATTTCC
\end{tabular}




\subsection{Statistical analyses}

Graphpad prism V5.0 software (Graphpad prism, CA, USA) was used for statistical analyses. All data were expressed as means \pm SEM. Comparisons of variants between experimental groups were conducted using One-way ANOVA, followed by the StudentNewman-Keuls test. Statistical significance was accepted when $p<0.05$.

\section{Results}

\subsection{Effects of GSE on body weight and pulmonary function}

BLM significantly decreased the body weight of mice. Treatment with GSE $100 \mathrm{mg} / \mathrm{kg}$ had a tendency to prevent the body weight loss three weeks after drug administration, but it was not statistically significant. Meanwhile, the positive control-DXM $0.5 \mathrm{mg} / \mathrm{kg}$-significantly reduced BLM-induced body weight loss $(p<0.05 \sim 0.01$ ) (Fig. 1A).

A total of 50 mice were randomly allocated into 5 groups of 10 mice/group; two mice of model group (BLM+saline) and one mouse of BLM + GSE $50 \mathrm{mg} / \mathrm{kg}$ group died for serious lung fibrotic pathology at day 15, 18 and 20 after intratracheal instillation of BLM, respectively.

Baseline Penh values were significantly higher in the BLMtreated model group than in the control group (Fig. 1B). GSE at $100 \mathrm{mg} / \mathrm{kg}$ and the anti-inflammatory drug, DXM, at $0.5 \mathrm{mg} / \mathrm{kg}$ significantly improved pulmonary function and inhibited the BLMinduced an increase in Penh value $(p<0.01)$, whereas $50 \mathrm{mg} / \mathrm{kg}$ GSE had no such effects (Fig. 1B).

\subsection{GSE reduces pulmonary inflammation, cytokines and lactate dehydrogenase $(L D H)$ activity}

After the last drug administration, BALF was harvested. Inflammatory cells in BALF were counted and compared across the treatment groups. As shown in Fig. 2, the total cell number in the BLM-treated model group was much higher than the control group ( $p<0.001$ ) (Fig. 2A); particularly, neutrophils, macrophages, and lymphocytes were significantly higher in the model group than in the control group ( $p<0.001)$ (Fig. 2B). Treatment with GSE at 50 or $100 \mathrm{mg} / \mathrm{kg}$ significantly reduced the numbers of total inflammatory cells compared to the model group $(p<0.05, p<0.01$ or $p<0.001)$. Particularly, GSE at 50 or $100 \mathrm{mg} / \mathrm{kg}$ significantly reduced the accumulation of neutrophil $(p<0.05)$ and macrophage $(p<0.01$ or $p<0.05)$ compared to the model group. The effects of GSE treatment at $50 \mathrm{mg} / \mathrm{kg}$ were comparable to dexamethasone treatment at $0.5 \mathrm{mg} / \mathrm{kg}$ (Fig. 2B).

To evaluate the effects of GSE on BLM-induced pulmonary inflammation, lung sections were stained with $\mathrm{H} \& \mathrm{E}$. Light microscopy and semi-quantitative analysis of inflammatory lesions in lung tissues were performed for the five experimental groups. We predominately observed inflammatory cell infiltration formation, including macrophages, neutrophils, and lymphocytes, in the lungs of the model group (Fig. 2C,D). The sections of lung tissue in the control group showed a normal mesh structure with histological characteristics, appearing as many polygonal alveoli separated by thin interalveolar septa (Fig. 2C). However, intratracheal injection of BLM led to inflammatory responses that were orchestrated, in large part, by neutrophil and macrophage infiltration in the lungs of the model group. Inflammatory reactions, such as edema, inflammatory cell infiltration, vascular congestion, and thickened septa, were observed in the model group (Fig. 2C). These reactions continuously caused inflammatory cells to migrate to the inflammatory foci, where they enhanced the lung injury and repair processes, which contributed to the fibrotic processes. Treatment with $100 \mathrm{mg} / \mathrm{kg}$ GSE markedly attenuated the inflammatory cell infiltration compared to the model group, which was comparable to the effects of DXM $0.5 \mathrm{mg} / \mathrm{kg}$ (Fig. 2C,D).

To investigate the effects of GSE on BLM-induced inflammatory cytokine expression, lung tissues were collected $24 \mathrm{~h}$ after the last drug administration. IL-6 and IL-1 $\beta$ mRNA expression were measured using qRT-PCR. As shown in Fig. 2E, GSE 50, $100 \mathrm{mg} /$ $\mathrm{kg}$ and DXM $0.5 \mathrm{mg} / \mathrm{kg}$ significantly inhibited IL-6 and IL-1 $\beta$ mRNA expression.

LDH activity was used to determine the cytotoxicity induced by BLM exposure (Fig. 2F). BLM-exposed mice displayed significantly higher LDH levels in the BALF than control mice, GSE $50 \mathrm{mg} / \mathrm{kg}$ and $100 \mathrm{mg} / \mathrm{kg}$, as well as DXM at $0.5 \mathrm{mg} / \mathrm{kg}$, significantly reduced the BLM-induced LDH elevation.
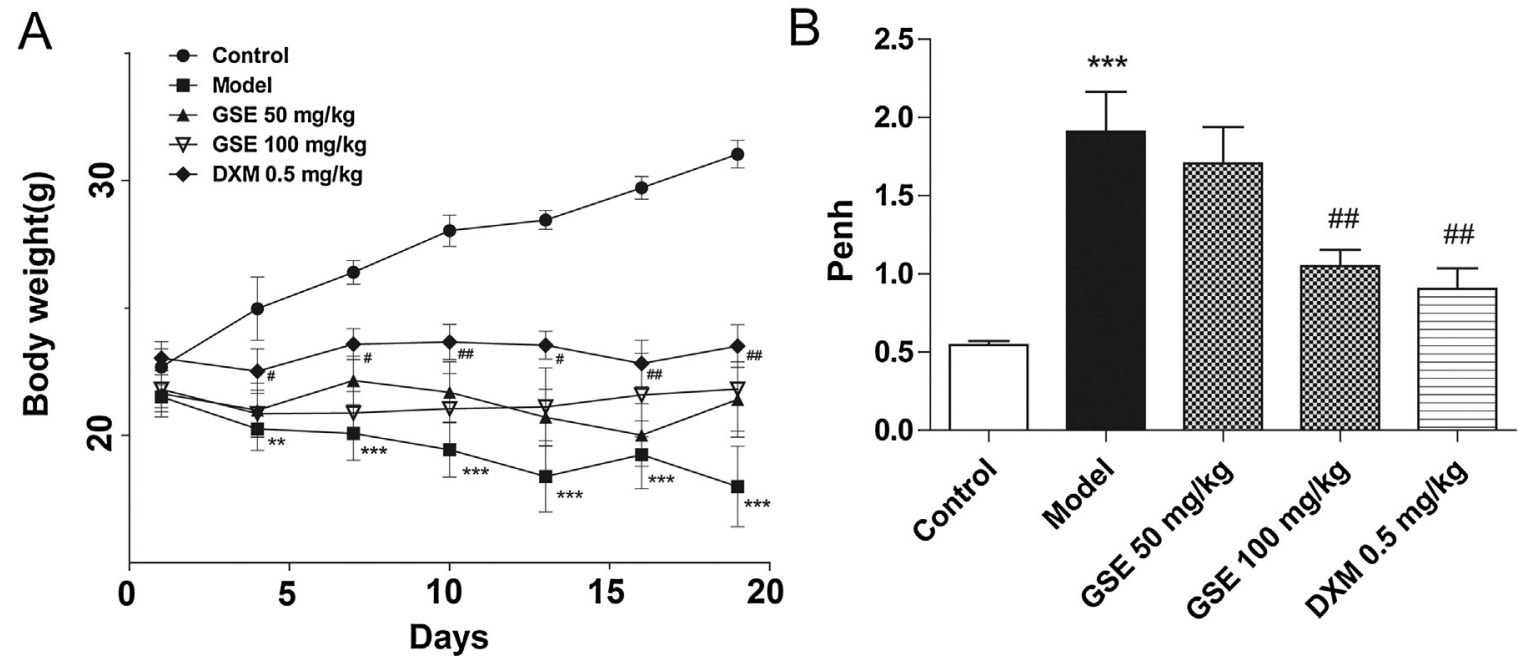

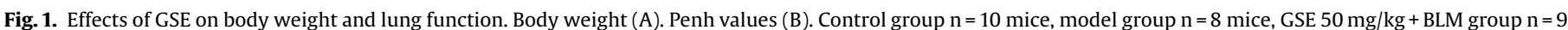

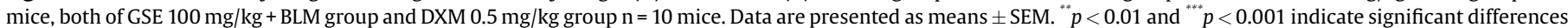

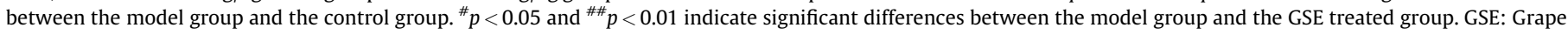
seed extract; BLM: Bleomycin; DXM: Dexamethasone $0.5 \mathrm{mg} / \mathrm{kg}$. 

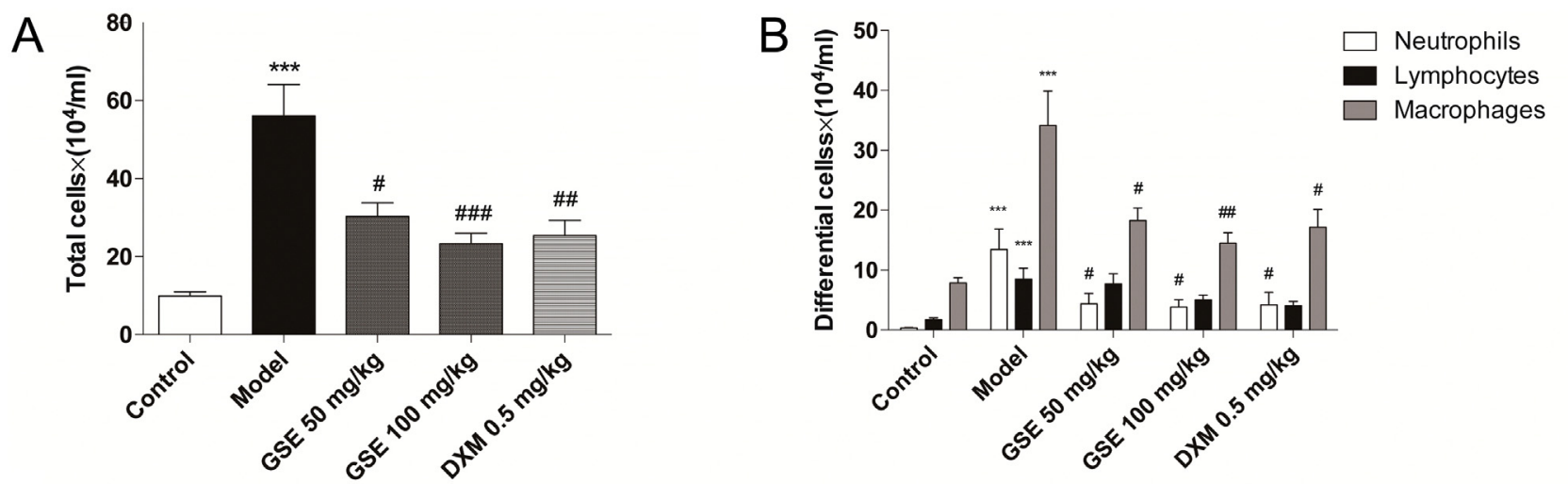

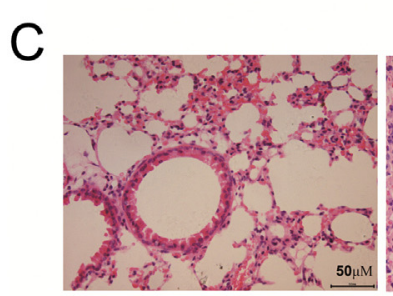

Control

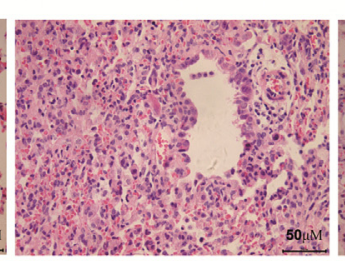

Model

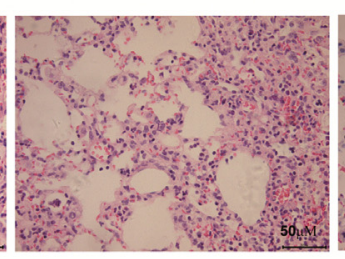

GSE $50 \mathrm{mg} / \mathrm{kg}$

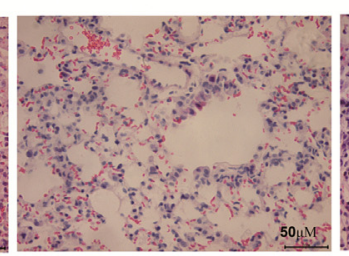

GSE $100 \mathrm{mg} / \mathrm{kg}$

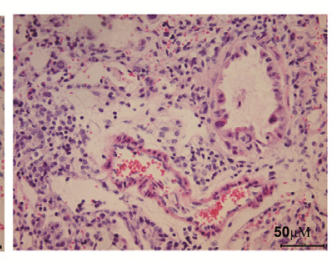

DXM $0.5 \mathrm{mg} / \mathrm{kg}$
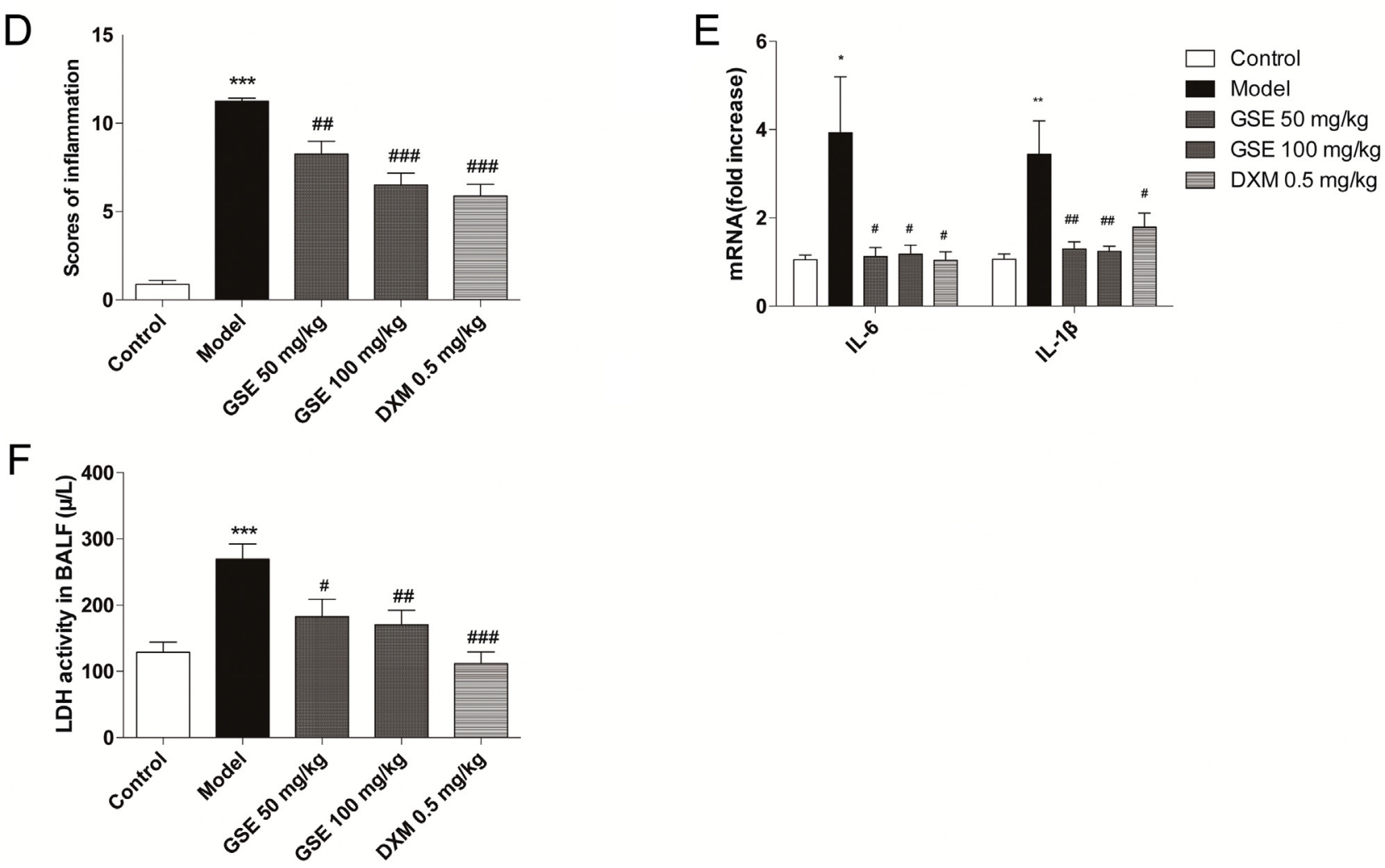

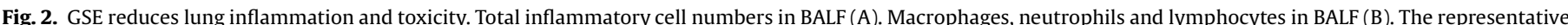

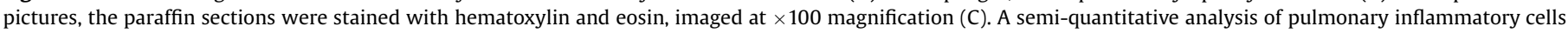

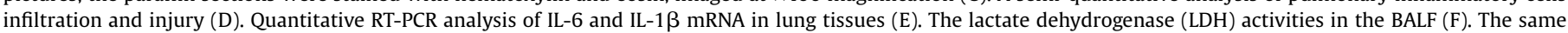

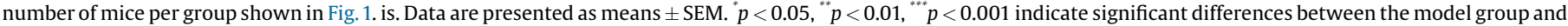
the control group. ${ }^{\#} p<0.05,{ }^{\# \#} p<0.01,{ }^{\# \# \#} p<0.001$ indicate significant differences between the model group and the treated group.

\subsection{GSE attenuates collagen deposition in lung tissues}

To evaluate the effects of GSE on BLM-induced fibrosis, lung sections were stained using Masson-stained assays. Light microscope imaging and semi-quantitative analysis of fibrotic lesions in lung tissue were performed for the five experimental groups.
Histological alterations were observed in BLM-induced lung fibrotic mice. BLM treatment resulted in the emergence of thicker-walled alveoli with small diameters, which were significantly different from the control group (Fig. 3A). The thickened septa showed accumulations of collagen deposition (blue staining) in lung tissues compared to the model group (Fig. $3 \mathrm{~B}, p<0.001$ ). 


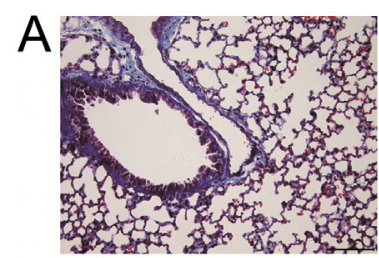

Control

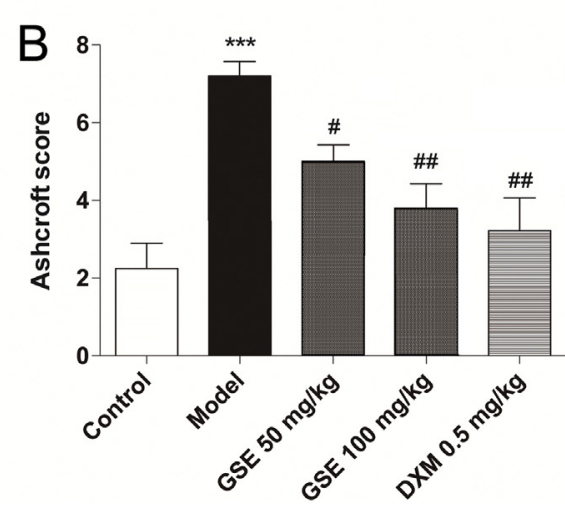

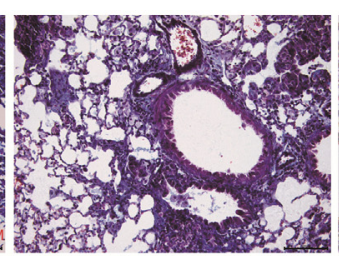

GSE $50 \mathrm{mg} / \mathrm{kg}$

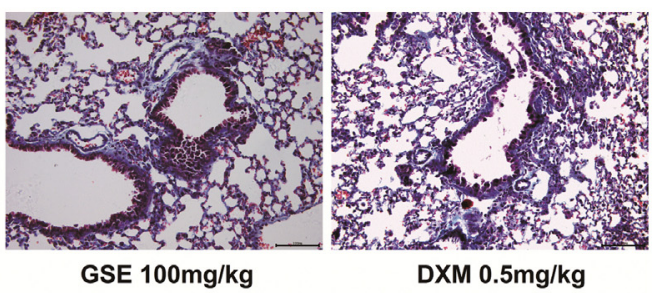

C

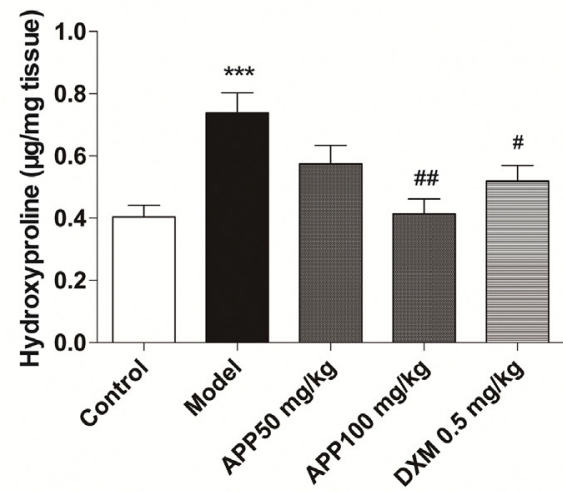

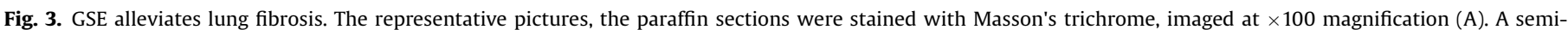

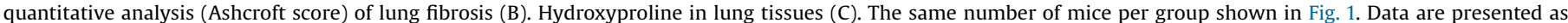

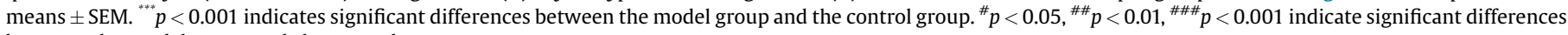
between the model group and the treated group.
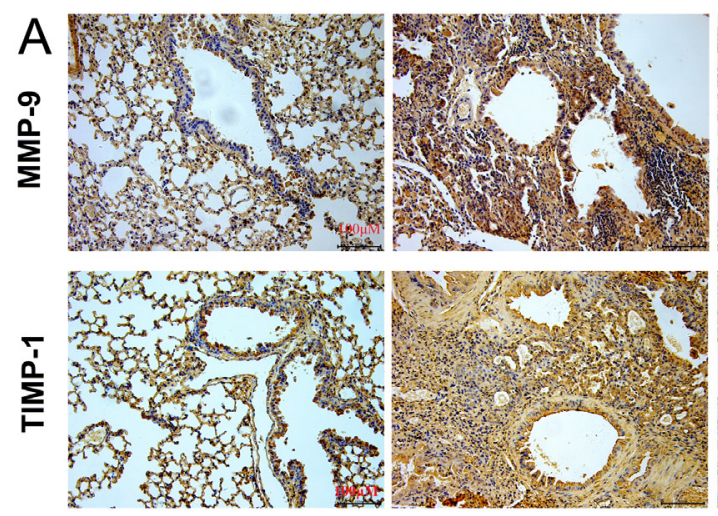

Control

Model
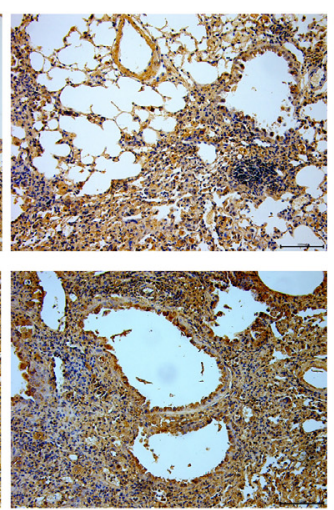

GSE $50 \mathrm{mg} / \mathrm{kg}$
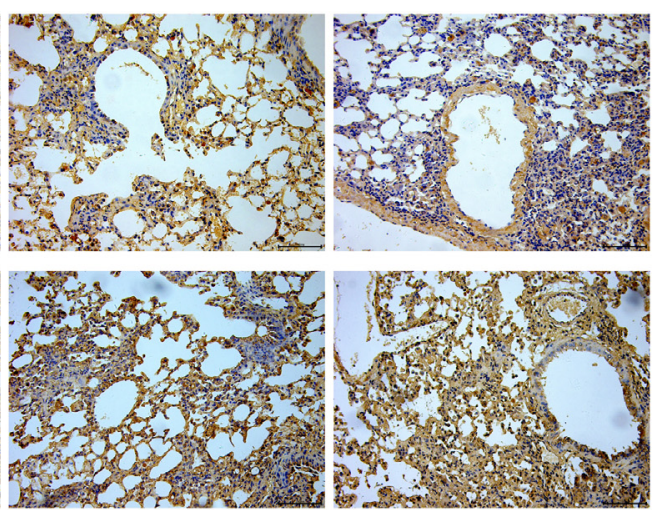

GSE $100 \mathrm{mg} / \mathrm{kg}$

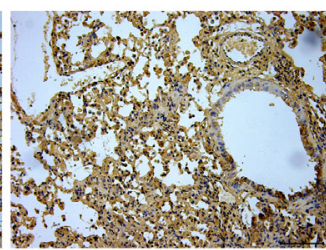

DXM $0.5 \mathrm{mg} / \mathrm{kg}$
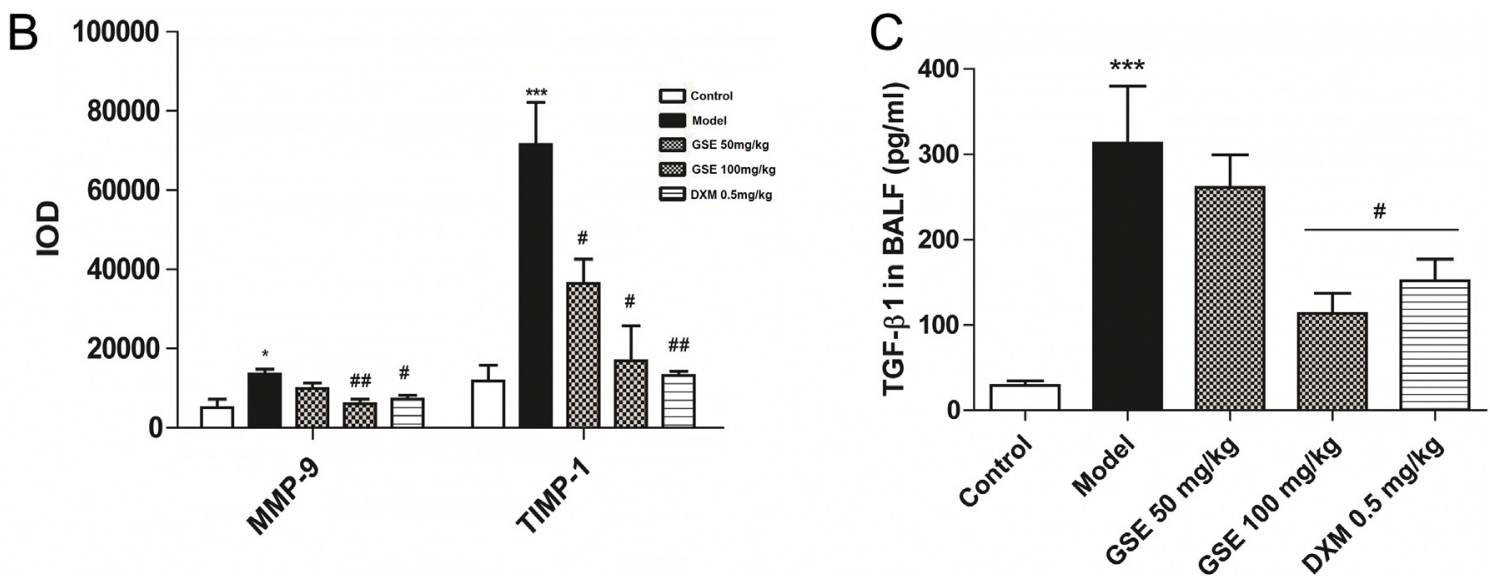

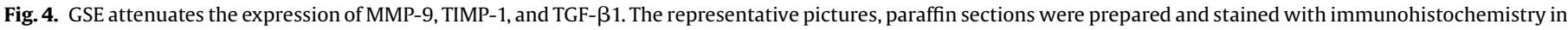

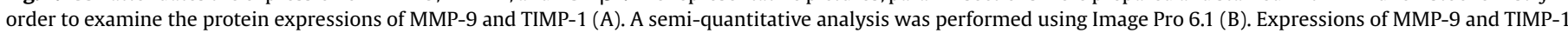

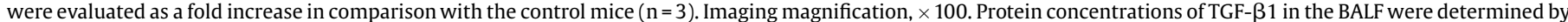

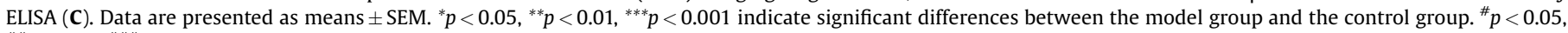
${ }^{\# \#} p<0.01,{ }^{\# \# \# p} p 0.001$ indicate significant differences between the model group and the treated group. 
However, treatment with GSE $50 \mathrm{mg} / \mathrm{kg}$ or $100 \mathrm{mg} / \mathrm{kg}$ markedly attenuated collagen deposition, where the effects of GSE $100 \mathrm{mg} /$ $\mathrm{kg}$ were comparable to those of DXM $0.5 \mathrm{mg} / \mathrm{kg}$.

We also examined the content of HYP, a major constituent of collagen in the lung tissues (Fig. 3C). The results showed elevated lung HYP levels in the model group, compared to the control group $(p<0.001)$. As shown in Fig. 3C, GSE $50 \mathrm{mg} / \mathrm{kg}$ or $100 \mathrm{mg} / \mathrm{kg}$ significantly attenuated BLM-induced increase in HYP $(p<0.01)$.

\subsection{GSE alleviates metalloproteinase and TGF- $\beta 1$ protein expression}

After the last drug administration, MMP-9 and TIMP-1 protein expression were examined by immunohistochemistry. We found an increase in both MMP-9 and TIMP-1 expression following BLM treatment in lung tissues, which were significantly alleviated by treatment with 50 or $100 \mathrm{mg} / \mathrm{kg}$ GSE (Fig. $4 \mathrm{~A}$ and B). Notably, the potency of GSE treatment at $100 \mathrm{mg} / \mathrm{kg}$ was comparable to that of DXM $0.5 \mathrm{mg} / \mathrm{kg}$. The level of TGF- $\beta 1$ protein in BLM-exposed mice was measured by ELISA. We found that TGF- $\beta 1$ levels in BALF were significantly elevated in the model group compared to the control group (Fig. 4C). GSE at $100 \mathrm{mg} / \mathrm{kg}$ or DXM at $0.5 \mathrm{mg} / \mathrm{kg}$, but not at
GSE $50 \mathrm{mg} / \mathrm{kg}$, markedly reduced TGF- $\beta 1$ protein expression (Fig. 4C).

\subsection{GSE regulates pulmonary EMT factors expression}

To investigate the effects of GSE on BLM-induced mRNA and protein expression of EMT factors, lung tissues were collected $24 \mathrm{~h}$ after the last intragastric administration. E-cadherin, COL1A1, and FN1 protein expression were examined using immunohistochemistry. We found a decrease in E-cadherin expression and an increase in both COL1A1 and FN1 expression. However, treatment with GSE 50 or $100 \mathrm{mg} / \mathrm{kg}$ and DXM $0.5 \mathrm{mg} / \mathrm{kg}$ significantly reversed BLM-induced changes of E-cadherin and COL1A1 expression in lung tissues compared to the model group (Fig. 5A,B). GSE at $100 \mathrm{mg} / \mathrm{kg}$ and DXM at $0.5 \mathrm{mg} / \mathrm{kg}$, but not at GSE $50 \mathrm{mg} / \mathrm{kg}$, significantly inhibited FN1 expression (Fig. 5A and B). Furthermore, we examined the mRNA expression of E-cadherin, COL1A1, and FN1 using Q-PCR. We found that GSE at $100 \mathrm{mg} / \mathrm{kg}$ and DXM at $0.5 \mathrm{mg} / \mathrm{kg}$ significantly increased the mRNA expression of E-cadherin, and reduced mRNA expression of COL1A1 and FN1 (Fig. 5C), which was consistent with the changes in protein expression.
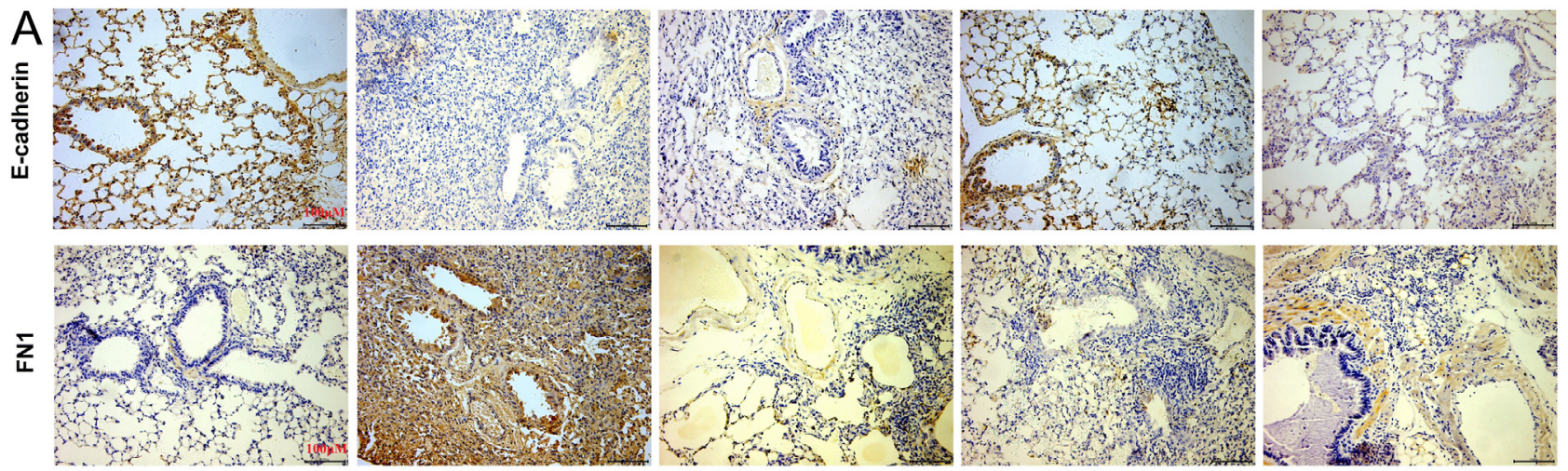

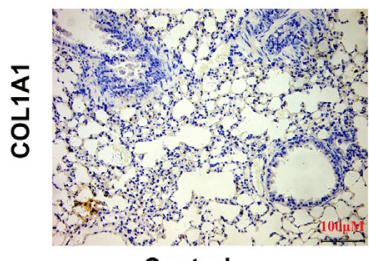

Control

$B$

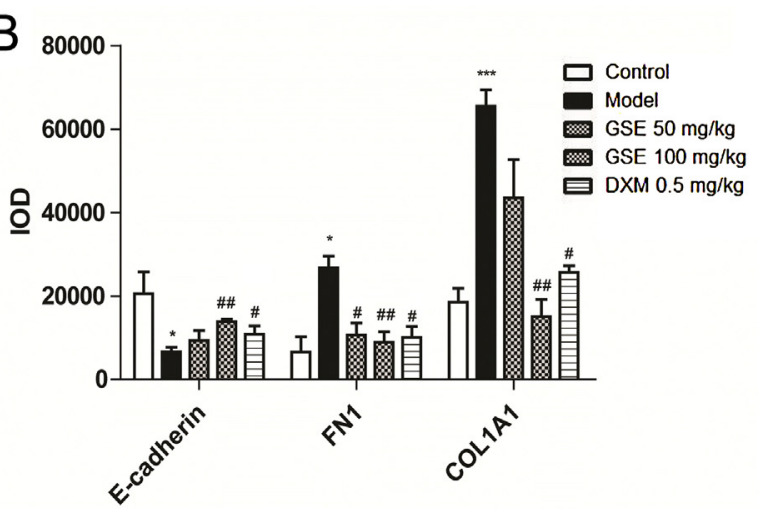

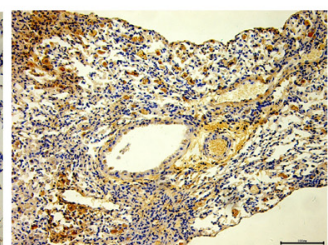

Model

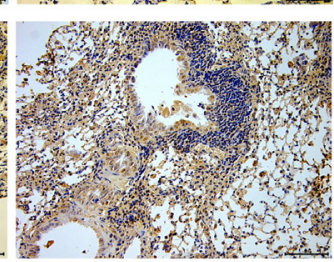

GSE $50 \mathrm{mg} / \mathrm{kg}$
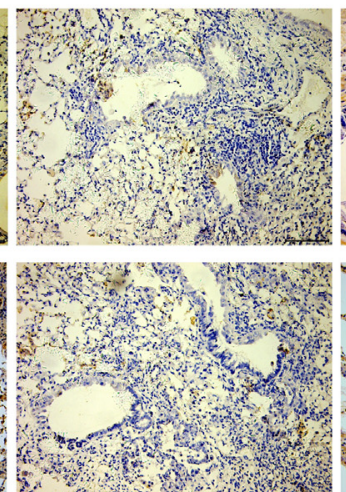

GSE $100 \mathrm{mg} / \mathrm{kg}$

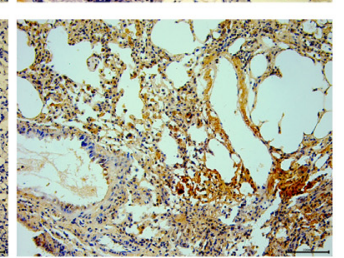

DXM $0.5 \mathrm{mg} / \mathrm{kg}$

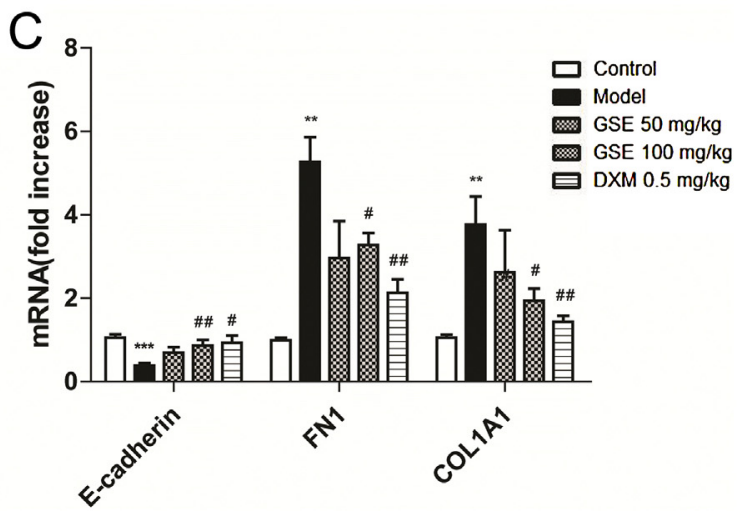

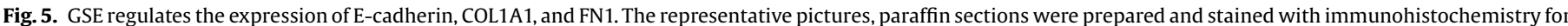

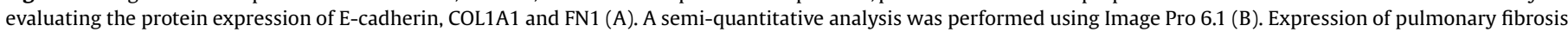

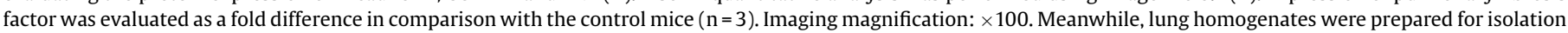

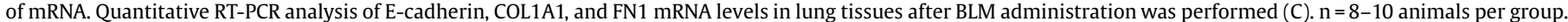

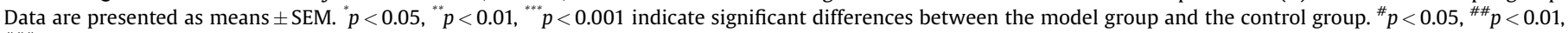
${ }_{\# \# \# p}<0.001$ indicate significant differences between the model group and the treated group. 


\section{Discussion}

In the present study, a BLM-induced lung fibrosis model was used to assess the anti-fibrotic effects of GSE, and to elucidate the underlying mechanisms. As expected, BLM induced a significant elevation of lung injury markers measured in BALF, including total and individual leucocyte count, in addition to a significant decline in relative lung function. Treatment with GSE at $100 \mathrm{mg} / \mathrm{kg} /$ day for three weeks starting at one day after bleomycin administration significantly decreased inflammatory, fibrotic lesions and Penh value in mice. Interestingly, we found GSE at the low dose $(50 \mathrm{mg} /$ $\mathrm{kg}$ ) can ameliorate some inflammatory and fibrotic indicators, but cannot improve lung function as read out by Penh. We suspect the mildly ameliorated inflammation and fibrotic could lead to a delayed improvement of lung function, which would be more likely to be detected at a later time point.

Hydroxyproline is a precursor of collagen, a key amino acid of collagen synthesis in the fibrotic lesions of mice. Compared to the control group, the model group exhibited an obvious enhancement in hydroxyproline levels in lung tissues, consistent with previous studies (Arizmendi et al., 2014; Zhao et al., 2010). The phenomenon of collagen deposition and accumulation in perialveolar and peribronchial tissues was also observed by analyzing images of the Masson's trichrome-stained sections. However, treatment with GSE at 50 or $10 \mathrm{mg} / \mathrm{kg}$ significantly ameliorated the histopathological characteristics of lung tissues in BLM-induced lung fibrosis in mice, suggesting that GSE prevents BLM-induced lung fibrosis. The anti-fibrotic effects of GSE are consistent with other studies using different animal models (Hemmati et al., 2008; Khazri et al., 2016).

Our second aim was to elucidate the underlying mechanisms behind the anti-fibrotic effects of GSE. We studied the effects of GSE on inflammatory and lung fibrotic markers in lungs. We know that the macrophages, neutrophils, and lymphocytes play critical roles in the development of fibrotic lesions in lungs upon BLM treatment (Cantin et al., 2015). Macrophages are a prominent cell type in pulmonary fibrotic processes, and can secrete a variety of profibrotic mediators, including platelet-derived growth factor, TGF- $\beta$, and reactive oxygen species (ROS). Neutrophil recruitment is also an important predictor of early mortality in IPF patients (Kinder et al., 2008). Studies on the BALF of patients with IPF have identified that these populations of inflammatory cells are present at high levels in the lungs. T-lymphocytes represent a relatively small population in a normal lung; however, they accumulate when pulmonary inflammation and fibrosis occur (Lo Re et al., 2013). In our study, we found that there is great accumulation of macrophages, neutrophils, and lymphocytes in the lungs following intratracheal instillation of BLM. We observe that these inflammatory cells facilitated the release of pro-inflammatory cytokines, such as IL-1 and IL-6, and is followed by an increased expression of pro-fibrotic markers (TGF- $\beta 1$, FN1, COL1A1). Notably, the lung tissues from GSE-treated mice showed a significant prevention from BLM-induced upregulation of IL- 1 and IL-6 protein levels, TGF- $\beta 1$, FN1, COL1A1 expression, and E-cadherin expression, indicating that GSE has an ameliorative role in BLM-induced pulmonary fibrosis.

Oxidative stress contributes to the development of pulmonary fibrosis by generating ROS, which further stimulate MMPs transcription. MMPs, as matrix degrading proteinases, have been shown to play important roles in pulmonary fibrosis. For example, an imbalance of MMPs and TIMPs may result in the initiation or progression of specific disease states, such as inflammation and fibrosis (Woessner, 1994). In the present study, we found that lung tissues in the model group had a significant increase in MMP-9 and TIMP-1 expression, which was significantly decreased by GSE treatment. Kobayashi et al.'s study demonstrated that MMP-9 can activate TGF- $\beta$, a potent fibrogenic growth factor causing pulmonary fibrosis, and stimulate fibroblast contraction of collagen gels (Kobayashi et al., 2014). In the present study, we confirmed that MMP-9 and TIMP-1 were over expressed in bronchiolar epithelial cells, fibrotic foci, and inflammatory cells in the lung tissues. Moreover, we also confirmed that TGF- $\beta 1$ was increased in BALF. In the $100 \mathrm{mg} / \mathrm{kg}$ GSE treated group, the structural remodeling of fibrotic areas and airways were less pronounced than in the model group. In addition, MMP-9 expression and TGF- $\beta 1$ levels in BALF, in the $100 \mathrm{mg} / \mathrm{kg}$ GSE group, were close to those of the model group. Therefore, our results suggest that GSE can prevent MMP-9 and TGF- $\beta 1$ production via BLM stimulation. Furthermore, the activation of TGF- $\beta 1$ and MMP-9 is the major factor that stimulates the transcription of COL1A1 and FN1 genes or inhibits the transcription of the E-cadherin gene (Betsuyaku et al., 2000; Cutroneo et al., 2007). Consistently, we also found an increase in the gene translation and protein expression of COL1A1 and FN1, and a decrease in E-cadherin in BLM-induced pulmonary fibrosis. However, GSE treatment resulted in a decrease in the gene translation and protein expression of COL1A1 and FN1, as well as an increase in the gene translation and protein expression of $\mathrm{E}$ cadherin following the intratracheal instillation of BLM, which is presumably due to the reduced expression of MMP-9 and TGF- $\beta 1$.

In conclusion, GSE may consequently decrease the associated inflammation by attenuating inflammatory cytokines. GSE also may decrease the activation of TGF- $\beta 1$ and MMP-9, preventing an increase in pro-fibrotic markers such as COL1A1 and FN1 and attenuating a decrease in anti-fibrotic markers such as E-cadherin in the BLM induced pulmonary fibrosis model. Additional investigations are necessary to elucidate the full anti-fibrotic potentials of GSE as a concomitant therapy for patients with lung fibrosis, including that produced during BLM treatment, especially with regard to timing its administration.

\section{Conflicts of interest}

The author(s) declare that they have no potential conflicts of interest with respect to the research, authorship, and/or publication of this article.

\section{Author's contributions}

YS, QMX and QL conceived and designed the experiments. QL, JXJ, YNL, LTG, YG, WZ, YLJ and XWD performed the experiments. QL, YNL and JXJ analyzed the data, QL, JXJ and QMX wrote the paper. All authors read and approved the final manuscript.

\section{Acknowledgments}

This work was supported by grants from the National Science Foundation of China (Nos. 81270095, 81373224, 81573439 and 81603117).

\section{References}

Agackiran, Y., Gul, H., Gunay, E., Akyurek, N., Memis, L., Gunay, S., Sirin, Y.S., Ide, T., 2012. The efficiency of proanthocyanidin in an experimental pulmonary fibrosis model: comparison with taurine. Inflammation 35, 1402-1410.

Arizmendi, N., Puttagunta, L. Chung K.L, Davidson, C. Rey-Parra, J., Chao, D.V. Thebaud, B., Lacy, P., Vliagofts, H., 2014. Rac2 is involved in bleomycin-induced lung inflammation leading to pulmonary fibrosis. Resp. Res. 15, 71.

Ashcroft, T., Simpson, J.M., Timbrell, V., 1988. Simple method of estimating severity of pulmonary fibrosis on a numerical scale. J. Clin. Pathol. 41, 467-470.

Bagnato, G., Harari, S., 2015. Cellular interactions in the pathogenesis of interstitial lung diseases. Eur. Respir. Rev. 24, 102-114

Bentivegna, S.S., Whitney, K.M., 2002. Subchronic 3-month oral toxicity study of grape seed and grape skin extracts. Food Chem. Toxicol. 40, 1731-1743. 
Betsuyaku, T., Fukuda, Y., Parks, W.C., Shipley, J.M., Senior, R.M., 2000. Gelatinase B is required for alveolar bronchiolization after intratracheal bleomycin. Am. J. Pathol. 157, 525-535.

Cantin, A.M., Hartl, D., Konstan, M.W., Chmiel, J.F., 2015. Inflammation in cystic fibrosis lung disease: pathogenesis and therapy. J. Cyst. Fibros. 14, 419-430.

Cutroneo, K.R., White, S.L., Phan, S.H., Ehrlich, H.P., 2007. Therapies for bleomycin induced lung fibrosis through regulation of TGF beta1 induced collagen gene expression. J. Cell. Physiol. 211, 585-589.

Dominguez-Fandos, D., Ferrer, E., Puig-Pey, R., Carreno, C., Prats, N., Aparici, M., Musri, M.M., Gavalda, A., Peinado, V.I., Montserrat, M., Barbera, J.A., 2014. Effects of aclidinium bromide in a cigarette smoke-Exposed Guinea pig model of chronic obstructive pulmonary disease. Am. J. Resp. Cell. Mol. 50, 337-346.

Gao, L., Tang, H., He, H., Liu, J., Mao, J., Ji, H., Lin, H., Wu, T., 2015. Glycyrrhizic acid alleviates bleomycin-induced pulmonary fibrosis in rats. Front. Pharmacol. 6, 215.

Garavaglia, J., Markoski, M.M., Oliveira, A., Marcadenti, A., 2016. Grape seed oil compounds: biological and chemical actions for health. Nutr. Metab. Insights 9, 59-64.

He, H., Tang, H., Gao, L., Wu, Y., Feng, Z., Lin, H., Wu, T., 2015. Tanshinone IIA attenuates bleomycin-induced pulmonary fibrosis in rats. Mol. Med. Rep. 11, 4190-4196.

Hemmati, A.A., Aghel, N., Nazari, Z., Mohammadian, B., Hasanvand, N., 2006. Protective effect of grape seed extract against the fibrogenic effect of bleomycin in rat lung. Iran. J. Pharm. Sci. 2, 143-150.

Hemmati, A.A., Nazari, Z., Samei, M., 2008. A comparative study of grape seed extract and vitamin E effects on silica-induced pulmonary fibrosis in rats. Pulm. Pharmacol. Ther. 21, 668-674.

Hoymann, H.G., 2007. Invasive and noninvasive lung function measurements in rodents. J. Pharmacol. Toxicol. Methods 55, 16-26.

Martinez, F.J., de Andrade, J.A., Anstrom, K.J., King Jr., T.E., Raghu, G., 2014. Randomized trial of acetylcysteine in idiopathic pulmonary fibrosis. N. Engl J. Med. 370, 2093-2101.

Khazri, O., Charradi, K., Limam, F., El May, M.V., Aouani, E., 2016. Grape seed and skin extract protects against bleomycin-induced oxidative stress in rat lung. Biomed. Pharmacother. 81, 242-249.

Kim, S.R., Kim, D.I., Kang, M.R., Lee, K.S., Park, S.Y., Jeong, J.S., Lee, Y.C., 2013. Endoplasmic reticulum stress influences bronchial asthma pathogenesis by modulating nuclear factor kappa B activation. J. Allergy Clin. Immunol. 132, 1397-1408.

Kinder, B.W., Brown, K.K., Schwarz, M.I., Ix, J.H., Kervitsky, A., King, T.E., 2008. Baseline BAL neutrophilia predicts early mortality in idiopathic pulmonary fibrosis. Chest 133, 226-232.

King, T.E., Tooze, J.A., Schwarz, M.I., Brown, K.R., Cherniack, R.M., 2001. Predicting survival in idiopathic pulmonary fibrosis: scoring system and survival model. Am. J. Resp. Crit. Care 164, 1171-1181.

Kobayashi, T., Kim, H., Liu, X., Sugiura, H., Kohyama, T., Fang, O. Wen, F.Q, Abe, S. Wang, X., Atkinson, J.J., Shipley, J.M., Senior, R.M., Rennard, S.I., 2014. Matrix metalloproteinase-9 activates TGF-beta and stimulates fibroblast contraction of collagen gels. Am. J. Physiol. Lung Cell. Mol. Physiol. 306, L1006-L1015.

Lo Re, S., Lison, D., Huaux, F., 2013. CD4+ T lymphocytes in lung fibrosis: diverse subsets, diverse functions. J. Leukoc. Biol. 93, 499-510.

Lundblad, L., Irvin, C., Hantos, Z., Sly, P., Mitzner, W., Bates, J., 2007. Penh is not a measure of airway resistance!. Eur. Respir. J. 30, 805.

Luo, S., Pauluhn, J., Trubel, H., Wang, C., 2014. Corticosteroids found ineffective for phosgene-induced acute lung injury in rats. Toxicol. Lett. 229, 85-92.

Mikawa, K., Nishina, K., Takao, Y., Obara, H., 2003. ONO-1714, a nitric oxide synthase inhibitor, attenuates endotoxin-induced acute lung injury in rabbits. Anesth. Analg. 97, 1751-1755.

Nassiri-Asl, M., Hosseinzadeh, H., 2009. Review of the pharmacological effects of vitis vinifera (Grape) and its bioactive compounds. Phytother. Res. 23, 11971204.

Qin, X.J., Zhang, G.S., Zhang, X., Qiu, Z.W., Wang, P.L., Li, Y.W., Li, W., Xie, Q.M., Ke, Y.H., Lee, J.J., Shen, H.H., 2012. Protein tyrosine phosphatase SHP2 regulates TGF-beta
1 production in airway epithelia and asthmatic airway remodeling in mice. Allergy 67, 1547-1556.

Raghu, G., Collard, H.R., Egan, J.J., Martinez, F.J., Behr, J., Brown, K.K., Colby, T.V., Cordier, J.F., Flaherty, K.R., Lasky, J.A., Lynch, D.A., Ryu, J.H., Swigris, J.J., Wells, A. U., Ancochea, J., Bouros, D., Carvalho, C., Costabel, U., Ebina, M., Hansell, D.M., Johkoh, T., Kim, D.S., King T.E.Jr. Kondoh, Y., Myers, J., Muller, N.L., Nicholson, A. G., Richeldi, L., Selman, M., Dudden, R.F., Griss, B.S., Protzko, S.L., Schunemann, H. J., 2011. An official ATS/ERSARS/ALAT statement: idiopathic pulmonary fibrosis: evidence-based guidelines for diagnosis and management. Am. J. Resp. Crit. Care. 183, 788-824.

Raghu, G., Anstrom, K.J., King Jr., T.E., Lasky, J.A., Martinez, F.J., 2012. Prednisone, azathioprine, and N-acetylcysteine for pulmonary fibrosis. N. Engl. J. Med. 366, 1968-1977.

Raghu, G., Rochwerg, B., Zhang, Y., Garcia, C.A.C., Azuma, A., Behr, J., Brozek, J.L., Collard, H.R., Cunningham, W., Homma, S., Johkoh, T., Martinez, F.J., Myers, J., Protzko, S.L., Richeldi, L., Rind, D., Selman, M., Theodore, A., Wells, A.U., Hoogsteden, H., Schunemann, H.J., 2015. An official ATS/ERS/JRS/ALAT clinical practice guideline: treatment of idiopathic pulmonary fibrosis an update of the 2011 clinical practice guideline. Am. J. Resp. Crit. Care 192, e3-e19.

Raghu, G., 2011. Idiopathic pulmonary fibrosis: guidelines for diagnosis and clinical management have advanced from consensus-based in 2000 to evidence-based in 2011. Eur. Respir. J. 37, 743-746.

Schwarzenberg, S.J., Hempstead, S.E., Mcdonald, C.M., Powers, S.W., Wooldridge, J., Blair, S., Freedman, S., Harrington, E., Murphy, P.J., Palmer, L., Schrader, A.E., Shiel, K., Sullivan, J., Wallentine, M., Marshall, B.C., Leonard, A.R., 2016. Entera tube feeding for individuals with cystic fibrosis: cystic Fibrosis Foundation evidence-informed guidelines. J. Cyst. Fibros. 15, 724-735.

Shen, H.J., Sun, Y.H., Zhang, S.J., Jiang, J.X., Dong, X.W., Jia, Y.L., Shen, J., Guan, Y., Zhang, L.H., Li, F.F., Lin, X.X., Wu, X.M., Xie, Q.M., Yan, X.F., 2014 Cigarette smokeinduced alveolar epithelial-mesenchymal transition is mediated by Rac1 activation. Biochim. Biophys. Acta 1838-1849.

Shi, K., Jiang, J., Ma, T., Xie, J., Duan, L., Chen, R., Song, P., Yu, Z., Liu, C., Zhu, Q., Zheng, J., 2014. Dexamethasone attenuates bleomycin-induced lung fibrosis in mice through TGF-beta, Smad3 and JAK-STAT pathway. Int. J. Clin. Exp. Med. 7, 26452650.

Sirinupong, N., Yang, Z., 2015. Bioactive food components as dietary intervention for cystic fibrosis. Curr. Drug Targets 16, 988-992.

Verheijden, K.T., Henricks, P.J., Redegeld, F.A., Garssen, J., Folkerts, G., 2014. Measurement of airway function using invasive and non-invasive methods in mild and severe models for allergic airway inflammation in mice. Front. Pharmacol. 5, 190.

Wei, X., Li, S., 2013. Progress of treating idiopathic pulmonary interstitial fibrosis by single Chinese drugs and their derivatives. Zhongguo Zhong xi yi jie he za zhi 33 , 420-424.

Woessner, J.F., 1994. The family of matrix metalloproteinases. Ann. N. Y. Acad. Sci. 732, 11-21.

Wren, A.F., Cleary, M., Frantz, C., Melton, S., Norris, L., 2002. 90-day oral toxicity study of a grape seed extract (IH636) in rats. J. Agric. Food Chem. 50, 2180-2192.

Xia, Y., Xia, Y.F., Lv, Q., Yue, M.F., Qiao, S.M., Yang, Y., Wei, Z.F., Dai, Y., 2016. Madecassoside ameliorates bleomycin-induced pulmonary fibrosis in mice through promoting the generation of hepatocyte growth factor via PPARgamma in colon. Br. J. Pharmacol. 173, 1219-1235.

Yara, S., Kawakami, K., Kudeken, N., Tohyama, M., Teruya, K., Chinen, T., Awaya, A., Saito, A., 2001. FTS reduces bleomycin-induced cytokine and chemokine production and inhibits pulmonary fibrosis in mice. Clin. Exp. Immunol. 124, 77-85.

Yoo, D.Y., Kim, W., Yoo, K.Y., Lee, C.H., Choi, J.H., Yoon, Y.S., Kim, D.W., Won, M.H., Hwang, I.K., 2011. Grape seed extract enhances neurogenesis in the hippocampal dentate gyrus in C57BL/6 mice. Phytother. Res. 25, 668-674.

Zhao, L., Wang, X., Chang, Q., Xu, J., Huang, Y., Guo, Q., Zhang, S., Wang, W., Chen, X., Wang, J., 2010. Neferine, a bisbenzylisoquinline alkaloid attenuates bleomycininduced pulmonary fibrosis. Eur. J. Pharmacol. 627, 304-312. 